\title{
Calorimetric efficiency determination of power electronic variable speed drives
}

\author{
Stan Caron ${ }^{a, b}$, Arne Berteyn ${ }^{a}$, Pieter Defreyne ${ }^{a, b}$, Steve Dereyne ${ }^{a, b}$ and Kurt \\ Stockman ${ }^{a, b}$
}

\author{
aDepartment of Electromechanical Systems and Materials, Ghent University \\ ${ }^{b}$ Member of Energy Efficient Drive Trains partner of Flanders Make, \\ www.eedt.ugent.be
}

\begin{abstract}
A calorimeter test bench for the efficiency and power loss determination of power electronic variable speed drives is presented. The balanced calorimetric setup with air as the cooling medium is proposed to test small electronic drives for $A C$ motors in a power range from $1 \mathrm{~kW}$ up to $7,5 \mathrm{~kW}$. The construction, the required measurement equipment, the measurement procedure and especially the measurement results and uncertainty are important aspects of this test bench and are discussed in this paper. The device under test is a 2,2kW drive which is measured using both the input-output method and the calorimetric method. The test results are compared and conclusions are made concerning usability, repeatability and accuracy of the test bench. The overall goal is to further examine and optimize the calorimetric approach and to be able to obtain more accurate and comparable test results of very high efficient frequency converters. This setup reaches an uncertainty of $\pm 2,39 \%$ or $\pm 1,48 \mathrm{~W}$ on the power loss at full load and speed using the calorimetric method.
\end{abstract}

\section{Introduction}

Variable speed drives come with very high efficiency values which makes it particularly difficult to accurately measure their low power losses. To address the efficiency of these converters or Complete Drive Modules (CDM), the IEC has developed the international standard IEC 61800-9-2 Ed. 1.0 b:2017 [1].

Three types of testing of CDM for IE classification are mentioned in the standard, i.e. the single component loss determination, the well-known input-output approach and the calorimetric measurement methodology. With the single component loss determination method, the loss is calculated. Detailed information on the components inside of the drive should be provided by the manufacturer to calculate the power loss, but this is usually not the case. This method is also called the semi-analytic model approach. The input-output method measures the electrical power extracted from the grid and the electrical output power delivered by the drive by using high end power analyzers. The last method mentioned in the standard is the calorimetric method which determines the power loss by measuring the heat loss or power dissipation of the CDM.

In the IEC 61800-9-2 standard, constant uncertainty is assumed for the single component loss determination and the calorimetric measurement [1]. The uncertainty of the single component loss determination method depends on the datasheet of the CDM which can be unavailable or not accurate. The uncertainty of the input-output method rises exponentially with respect to the increasing efficiency [1]. These aspects make the calorimetric approach attractive to overcome the uncertainty problems when accurate measurements of very high efficiency drives (>97\%) are required.

\section{Calorimeter concept}

The calorimetric measurement is a straightforward measurement method in which the losses are determined by measuring the heat loss of a device under test (DUT). The DUT is mounted in an insulated box which is heated up due to the power loss of the DUT. By measuring temperature changes, the amount of power or heat is determined as shown in (1). The power is absorbed by a cooling gas or liquid. The absorbed power $(\mathrm{P})$ is thus equal to the mass flow rate $(\dot{\mathrm{m}})$ multiplied by the average specific heat of the liquid or gas $\left(c_{p}\right)$ and the difference of temperature between the inlet and outlet $(\Delta T)$. 


$$
P=\dot{m} c_{p} \Delta T
$$

Different calorimetric concepts have been developed to be able to measure power electronic variable speed drives with a high accuracy [2]. There are two main approaches, i.e. direct and indirect calorimetry. Direct calorimeters measure the heat directly by measuring the parameters in (1) while indirect calorimeters determine the power loss indirectly by implementing an auxiliary heater. All of the types are explained in [2]. These types each have their own advantages and disadvantages but to achieve effective measurements with a calorimeter three main requirements must be met: a steady mass flow is needed, heat leakage has to be minimized and the coolant temperature has to be measured or controlled [2].

In this paper an air-cooled indirect balanced calorimeter test bench is introduced. The measurement consists of two tests: the main and balance test. During the main test, a DUT is powered and heating up the chamber. The balance test requires an additional heater. In this test the power of the heater is adjusted to achieve the same temperature rise of the coolant as during the steady state in the main test [3]. Both tests are performed in the same calorimetric chamber. Therefore this chamber contains both the DUT and the heater. The biggest advantage of this method is that the coolant properties do not change much because the main and balance tests are executed sequentially. Hence, measuring the coolant properties is not critical anymore. The measurement of electric DC power is easier than measuring the coolants properties which makes indirect calorimeters as the balance type interesting. However, due to the variation of the specific heat capacity when barometric pressure and air humidity change, the accuracy of the power measurement could be influenced [4]. This is taken into account in the test bench construction.

As mentioned in [2], the heat leakage through the walls of the box should be minimized. To minimize the heat leakage, thick insulated walls can be used to construct the box. However, due to thick insulation the thermal mass of the setup increases resulting in a longer time to reach a thermal equilibrium. [5]. One of the main disadvantage of calorimetric measurement is the test duration. So this aspect should be considered carefully. Equation (1) is expanded when the heat leakage is added to the formula, shown in (2)

$$
P_{\text {loss }, \text { DUT }}=\dot{m} * c_{p} * \Delta T+P_{\text {walls }}
$$

with $P_{\text {walls }}$ the power loss through the walls.

In the balance calorimeter concept, the mass flow rate $(\dot{m})$, the average specific heat capacity $\left(\mathrm{c}_{\mathrm{p}}\right)$ and temperature difference $(\Delta T)$ are not used to calculate the power loss of the device under test (PDUT). The power of the resistive heater ( $P_{\text {heater}}$ ) replaces the first part in (2) which results in (3) when calculating the power loss of the DUT. Notice that equation (3) is only accurate when the thermal conditions during the main test are identical compared with the balance test. A compensation power $\left(P_{\text {comp }}\right)$ can be added to (3) when there are differences in specific heat capacity during the thermal equilibria of the main and balance tests, resulting in (4). The difference in heat leakage through the walls ( $P_{\text {diff,walls }}$ ) should be added to (3) because the power leakage is almost never exactly the same during the main and balance test due to fluctuations of the ambient air temperature. If the heat leakage would be constant during the whole measurement, the power loss of the DUT should be equal to the heater power.

$$
P_{\text {loss }, \text { DUT }}=P_{\text {heater }}+P_{\text {diff }, \text { walls }}
$$

The heater can be used during the main test to increase the power in the box and thus decrease the measurement rate. The loss of the DUT is equal to (4) if every power is added to the power loss equation

$$
P_{\text {loss }, \text { DUT }}=P_{\text {heater }, \text { bal }}-P_{\text {heater }, \text { main }}+P_{\text {diff,walls }}+P_{\text {comp }}
$$

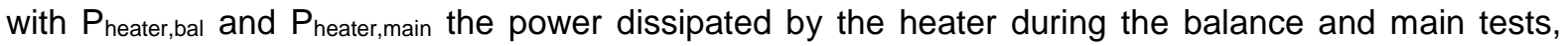
$P_{\text {diff,walls }}$ the difference in power leakage through the walls and $P_{\text {comp }}$ the compensation power due to variation of the thermal equilibria during the whole measurement.

To determine the efficiency with a calorimetric measurement, (5) is taken into account.

$$
\eta_{D U T}=\frac{P_{\text {out }}}{P_{\text {in }}}=\frac{P_{\text {in }}-P_{\text {loss }, D U T}}{P_{\text {in }}}
$$


with $\mathrm{P}_{\text {in }}$ the power input extracted from the grid, $\mathrm{P}_{\text {out }}$ the output power delivered to the motor and $\mathrm{P}_{\text {loss, DUT }}$ the power loss of the device under test.

\section{Test bench setup}

In this paper a balanced calorimetric setup with air as medium is proposed to test small electronic drives for $\mathrm{AC}$ motors in a power range from $1 \mathrm{~kW}$ up to $7,5 \mathrm{~kW}$. An efficiency and power loss determination is performed on a 2,2kW drive using the input-output and calorimeter method. These measurements are executed simultaneously in order to compare the results.

Figure 1 shows a schematic overview of the test bench. The variable speed drive on the drive side of the setup is measured by the input-output method with a PM6000 power analyzer. Thus, the input power extracted from the grid and the output power delivered to the drive motor are measured.

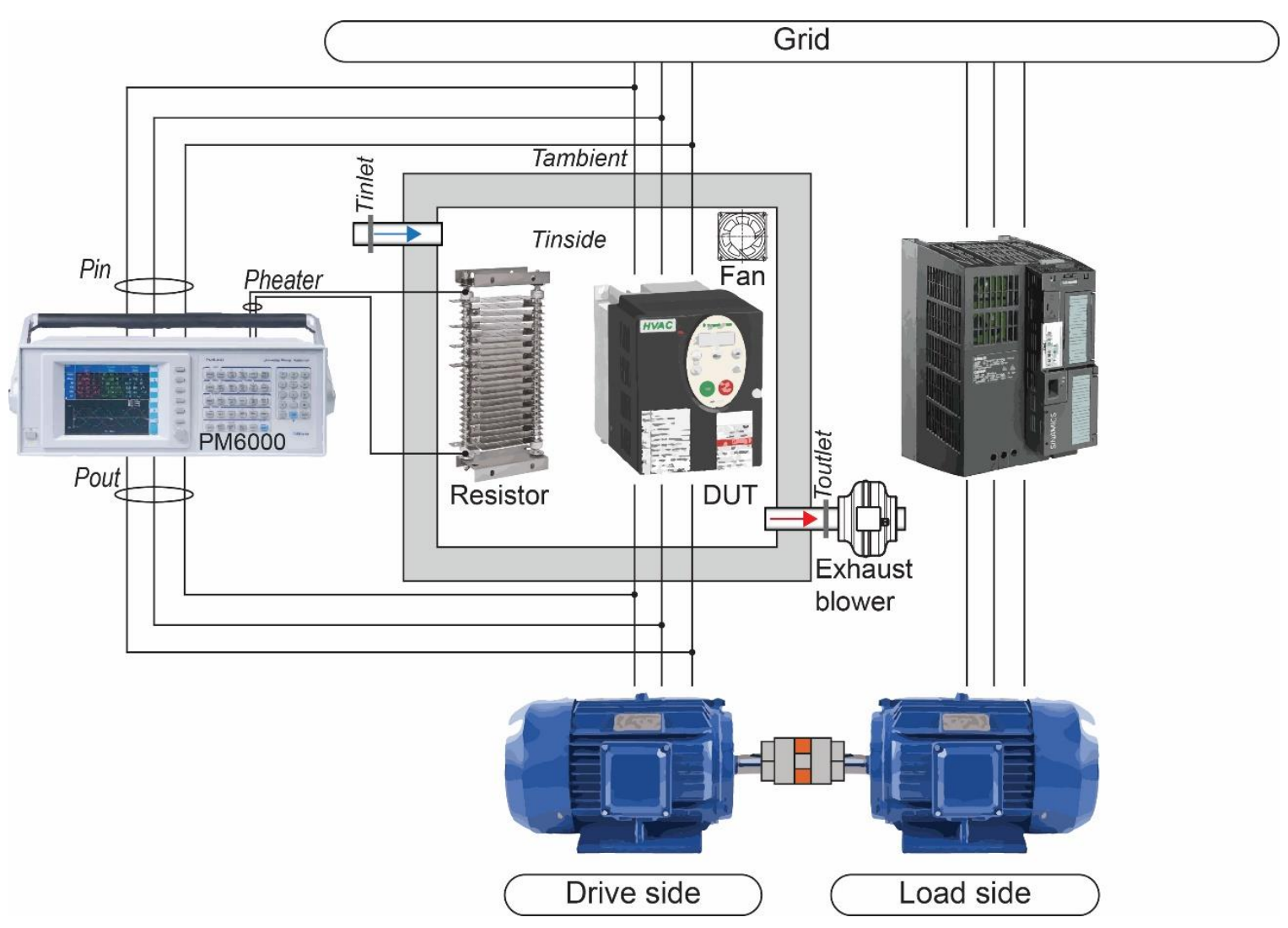

Figure 1: balance calorimeter test bench setup

The calorimetric measurement is performed at the same time. This setup consists of several parts (Fig.1). The box is constructed from insulation plates of $200 \mathrm{~mm}$ thick made out of polyurethane (PUR) with a thermal conductivity value $(\lambda)$ of $0,022 \mathrm{~W} / \mathrm{mK}$ and a thin layer of aluminum on both sides. These plates have three benefits i.e. the insulation value is very good so heat leakage is minimized, the plates are rigid and it is easy to make a box out of it and the aluminum layer increases heat conduction and the temperature is better distributed along the surface of the inside walls [2]. The outer dimensions of the box are $1,08 \mathrm{~m} \times 1,08 \mathrm{~m} \times 1,28 \mathrm{~m}$. The volume of the box has to be chosen so that it is large enough for the DUT, a heater, additional fans, temperature sensors and extra room for air displacement.

There are two holes in the box for the air inlet and outlet tubes with diameters of $40 \mathrm{~mm}$ for the inlet and $125 \mathrm{~mm}$ for the outlet, positioned in such a way that the distance of the airflow is as long as possible in the chamber. The inlet tube is located in the upper deepest corner of the box and the outlet tube is located in the lower corner near the front opening. This is to prevent separation of the air into layers of different temperature [3]. 
The inlet air is sucked out of a large basement because the air properties vary less than in the laboratory where the calorimeter is placed. In this setup the air properties are assumed to be constant but if variations in temperature occur, a compensation power is added to the power loss. The outlet air is blown into the ambient which causes the laboratory to warm up and thus causes instabilities in the power leakage through the walls. Therefore, the difference in power leakage during the main and balance tests is also added to the power loss, as seen in (3).

The temperature of the inlet and outlet air is measured with four temperature sensors each. The average of those four sensors is then used to calculate the mean inlet and outlet temperature. The inside temperature, on the other hand, is measured by a grid of six sensors while the ambient temperature is measured with one sensor outside the calorimeter. All of the temperature sensors used in this setup are A class, four wire pt100's with a tolerance of $\pm 0,15^{\circ} \mathrm{C}$.

Other parts in the calorimetric setup are the inside fans and the exhaust blower. $12 \mathrm{Vdc}$ fans are placed in the box to mix the air in such a way that the temperature is homogenous in the whole box. The inside fans are enabled during the main and balance test.

To move the air through the inlet tube, the calorimetric chamber and the outlet tube, an exhaust blower is attached to the outlet tube. When the blower in the outlet tube exhausts the air, a small vacuum occurs inside the chamber and therefore the air is circulating from the basement into the chamber and out into the ambient [5]. The blower is an electronically commutated motor of $85 \mathrm{~W}$, powered by the grid of $230 \mathrm{Vac}$. The nominal rotation speed is $3200 \mathrm{rpm}$ with a mass flow rate of approximately $415 \mathrm{~m} / \mathrm{h}$. The blower speed is controlled by an analogue signal of 0-10 V.

During the balance test a heater is needed which is a resistor in this setup. There is a heat sink mounted on top of the resistor to improve the heat transfer to the air. The $6,8 \Omega$ resistor is powered by a controlled DC voltage of $0-65 \mathrm{~V}$. Therefore the maximum possible heat dissipation is $500 \mathrm{~W}$ which defines the range of the calorimeter in theory. In practice, the range is around $350 \mathrm{~W}$ due to the maximum flow rate of the air in the setup.

In figure 1 the load side of the test bench can be seen as well. If the drive motor is connected to the load motor, the motor-generator cycle is complete and multiple setpoints can be measured.

\section{Measurement procedure}

A thorough measurement procedure (Fig. 2) is proposed to achieve accurate and reproducible results with the calorimetric test bench. The balance type of calorimetry consists of a two-step measurement procedure, i.e. the main and balance test phase. Before efficiency or power loss determination tests of a drive can be performed, the DUT is be mounted. Then the setup must be calibrated in order to accurately determine the power leakage. 


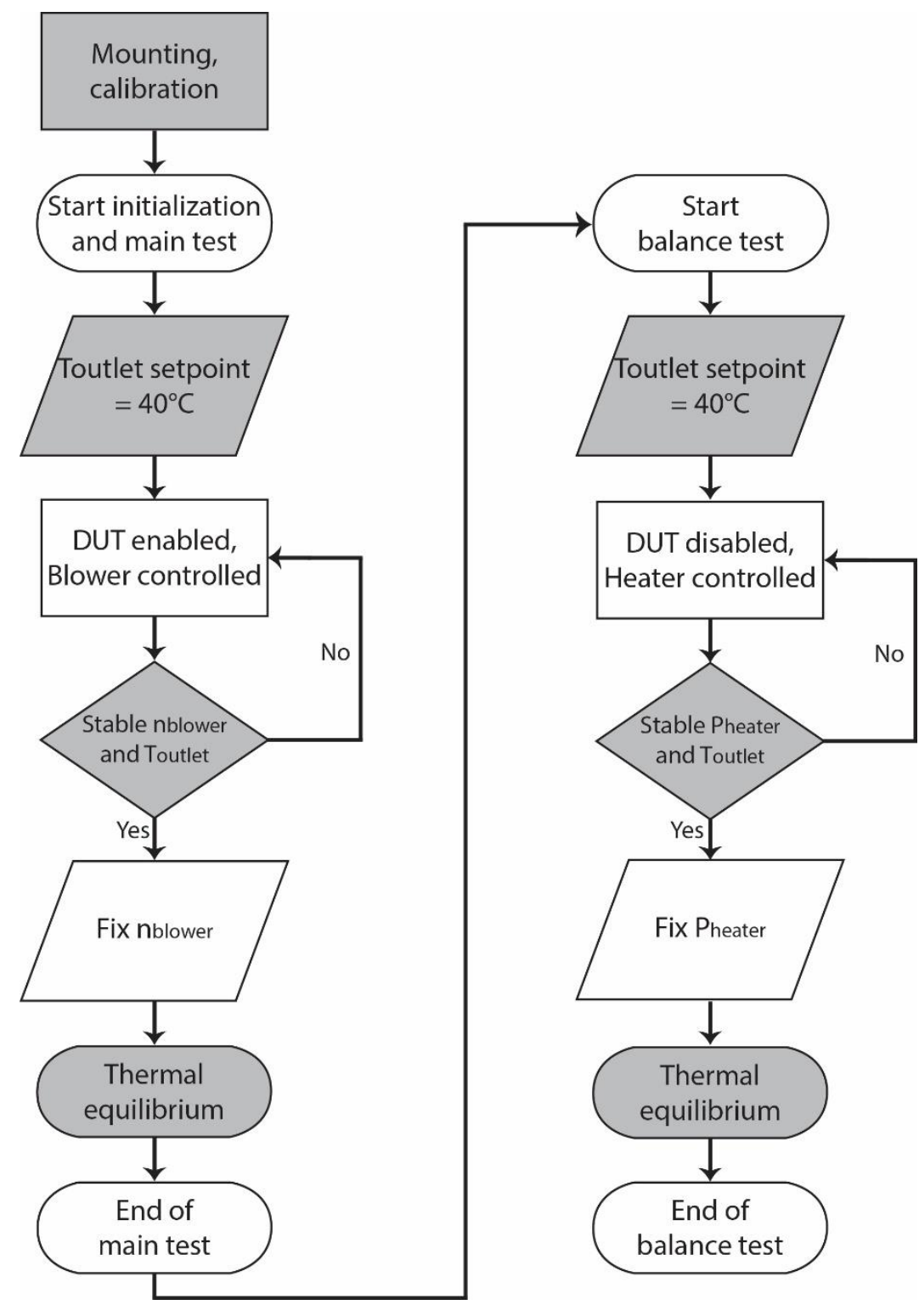

Figure 2: the flowchart of the measurement procedure

During the calibration, a constant amount of power is dissipated in the box by the heating element while a high end power analyzer with a basic uncertainty of $0,02 \%$ measures the input power. Both the inlet and outlet tubes are stuffed with insulation material. Thus, the heat circuit of the box is a closed circuit and the heat can only be lost through the walls of the calorimeter. The power loss through the walls $\left(P_{\text {walls }}\right)$ is equal to (6).

$$
P_{\text {walls }}=U_{\text {walls }} S_{\text {walls }} \Delta T_{\text {walls }}
$$

$U_{\text {walls }}$ is the overall heat transfer coefficient of the chamber. This coefficient depends on the insulation thickness (d) and the thermal conductivity $(\lambda)$ of the applied insulation material, as seen in (7).

$$
U_{\text {walls }}=\frac{\lambda}{d}
$$

The surface area of the calorimetric box is $\mathrm{S}_{\text {walls }}$ and $\Delta \mathrm{T}_{\text {walls }}$ is the temperature difference between the inside temperature of the chamber and the ambient temperature. The overall heat transfer coefficient of the chamber and the surface area are assumed to be constant. Therefore, if the temperature over the wall is measured, the power leakage can be calculated. A calibration should be performed to determine the correlation between the temperature over the walls and the power leakage. 
The difference in temperature over the walls of the calorimeter with respect to the heater power is seen on the calibration curve (Fig. 3). The curve is obtained by performing a linear fit on the results. The linear equation of the curve is used to determine the power leakage when the temperatures are measured, as shown in equation (8). The worst case or maximum error on the linear fit is $0,76 \mathrm{~W}$.

$$
P_{\text {walls }}=0,707 * \Delta T_{\text {walls }}-1.77
$$

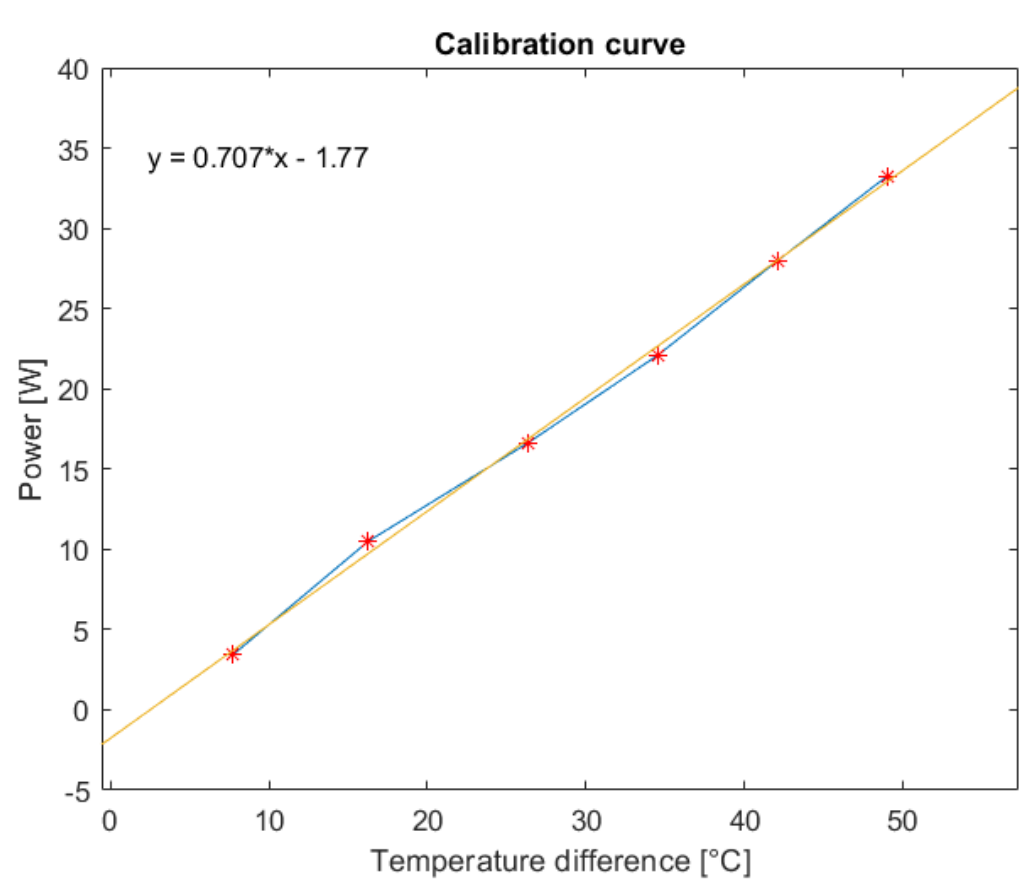

\section{Figure 3: calibration curve of the calorimeter setup}

The start of the actual measurement is the next step in the flowchart (Fig. 2). The initialization and main test are performed first. The calorimeter has a specific thermal mass which increases the measurement rate. During the initialization, the heating element produces extra heat in the calorimeter to decrease the test duration and overcome the thermal inertia problem. In practice, the heater produces $400 \mathrm{~W}$ the first 10 minutes of the test. After the initialization, the DUT, inlet and outlet tubes, the perforated plate, cables and insulation are heated up.

While the initialization is performed, the main test is already executed simultaneously. The DUT is powered on and the drive motor is controlled with a constant speed and loaded by the load side of figure 1. The drive is heating up the air inside the box because of its power loss. During the main test, the exhaust blower speed is PID controlled to reach a constant outlet air temperature of $40^{\circ} \mathrm{C}$. The blower sucks air into the inlet tube, through the calorimeter and out into the ambient. To maintain a minimum air circulation through the setup, the lower limit of the rotation speed is set on $15 \%$ of the maximum speed.

It should be noticed that the drive and load motor should also reach a thermal equilibrium. Therefore during the beginning of the test, the power loss of the DUT varies. The settling time of the electric motors is much smaller than the settling time of the calorimeter, hence, this is neglected.

After a while the exhaust blower speed settles $(\Delta$ nblower $<20 \mathrm{rpm})$ while the DUT is losing a constant amount of power and the outlet air remains equal to $40^{\circ} \mathrm{C}\left(\Delta \mathrm{T}_{\text {outlet }}<0.1^{\circ} \mathrm{C}\right)$. The rotation speed of the blower is fixed. A steady state or thermal equilibrium is reached. The inside and ambient temperature should also be stable to ensure a constant thermal condition of the calorimeter. 15 minutes of the thermal equilibrium are saved and analyzed before the main test is finished. Data points are saved every 10 seconds.

The second phase of the measurement is the balance test. The blower is rotating at fixed speed which is the value obtained from the thermal equilibrium during the main test. The outlet temperature setting value remains $40^{\circ} \mathrm{C}$. Next, the DUT is switched off and the heating element should then produce enough 
heat to achieve the same thermal conditions as during the main test. The power source of the heater is controlled during the balance test with a PID controller. Therefore, the heater is actually mimicking the DUT while the PID controller is searching for the same amount of power that the DUT was dissipating during the main test. When the temperatures and heater power are stable, the power source control of the heater is fixed and a new thermal equilibrium is achieved. The balance test is finished. The thermal conditions of both the main and balance test should be compared to conclude if the measurement has been successful. If necessary, a compensation power should be implemented to correct the results.

If the power loss of a DUT is very low, an extra power can be produced during the main test with the heater. Hence, the duration to reach the thermal equilibrium decreases but the uncertainty rises because the heater power has to be measured during both the main and balance test. The power loss of the inside fans is neglected because the fans are enabled throughout the whole measurement.

\section{Measurement uncertainty}

The measurement uncertainty of the input-output measurement method depends completely on the uncertainty calculation of the power analyzer. During the measurements in this paper, the PM6000 of Voltech is used with a base accuracy of $0,02 \%$. Compared to the input-output method, the uncertainty determination of a calorimeter is not so obvious.

The main interesting subject about the calorimetric concepts is the uncertainty of the measurement. The goal of this method is to achieve a higher accuracy compared with the direct method, especially when high efficiency devices are tested. As mentioned in [7], there is no standard method to calculate the uncertainty of calorimetric measurements. Therefore, comparing results of publications about this type of calorimetry is difficult. Also, a clear explanation of how the uncertainty should be calculated is not found. Hence, in this paper the uncertainty calculation of a measurement is explained clearly.

The measurement uncertainty consists of two types, e.g. the A-type and B-type uncertainties [8]. The A-types occur because of fluctuations in the measured values. They are derived from the standard deviation (s) of the mean (x). If the standard deviation is low, the variations on the mean are small and thus more accurate results are obtained. To calculate the standard A-type uncertainty of a measurement, equation (9) is implemented

$$
A F_{A}(x)=\frac{s}{\sqrt{n}}
$$

with $n$ the amount of readings and $\mathrm{AF}_{\mathrm{A}}(\mathrm{x})$ the $\mathrm{A}$-type absolute fault of the mean.

The A-type standard uncertainties are included in the results but not shown in detail.

B-type uncertainties depend on other causes than the A-type uncertainties as the uncertainties due to the measurement instruments and other parameters. In this balance calorimeter setup, the accuracy depends on the uncertainty of the temperature sensors and the power analyzer. The uncertainty due to the change of the air properties between the main and balance test is implemented in the uncertainty calculation. The humidity and pressure are not measured, therefore, the uncertainty of the air variation only depends on the temperature sensors. This could decrease the measurement accuracy [3].

The temperature sensors are accurate up to $\pm 0,15^{\circ} \mathrm{C}$. The uncertainty of the reading is also equal to $\pm 0,15^{\circ} \mathrm{C}$ which makes the total uncertainty of the temperature measurements equal to (10)

$$
A F_{B}(T)=\sqrt{\left(\frac{0,15^{\circ} C}{\sqrt{n_{s}}}\right)^{2}+\left(0,15^{\circ} C\right)^{2}}
$$

where $n_{s}$ is the number of sensors. The uncertainty of the different temperature measurements are found in table 1. 
Table 1: accuracy of the temperature measurements

\begin{tabular}{|l|r|r|}
\hline Temperature Measurement & Number of Sensors & Uncertainty \\
\hline Inlet & 4 & $\mathrm{AF}\left(\mathrm{T}_{\text {inlet }}\right)=0,17^{\circ} \mathrm{C}$ \\
\hline Outlet & 4 & $\mathrm{AF}\left(\mathrm{T}_{\text {outlet }}\right)=0,17^{\circ} \mathrm{C}$ \\
\hline Inside & 6 & $\mathrm{AF}\left(\mathrm{T}_{\text {inside }}\right)=0,16^{\circ} \mathrm{C}$ \\
\hline Ambient & 1 & $\mathrm{AF}\left(\mathrm{T}_{\text {ambient }}\right)=0,21^{\circ} \mathrm{C}$ \\
\hline
\end{tabular}

To measure the DC power dissipated by the balance heater, the PM6000 power analyzer is applied. (11) is used to calculate the total uncertainty on the measured power loss of the DUT while (12) shows the uncertainty equation for the efficiency determination. It is important to notice that the accuracy of the efficiency determination also depends on the input power measurement, as seen in (5).

$$
\begin{gathered}
A F\left(P_{\text {loss }, \text { DUT }}\right)=\sqrt{A F\left(P_{\text {heater }, \text { bal }}\right)^{2}+A F\left(P_{\text {heater }, \text { main }}\right)^{2}+A F\left(P_{\text {diff }, \text { walls }}\right)^{2}+A F\left(P_{\text {comp }}\right)^{2}} \\
R F\left(\eta_{\text {DUT }}\right)=\sqrt{R F\left(P_{\text {in }}\right)^{2}+R F\left(P_{\text {in }}-P_{\text {loss }, D U T}\right)^{2}}
\end{gathered}
$$

The uncertainty of the heater power ( $\mathrm{P}$ heater) is calculated as stated in the datasheet of the PM6000.

Next, the uncertainty of the power leakage through the walls should be calculated which is not evident. As shown in (6) the power loss depends on the overall heat transfer coefficient, the surface area and the temperature difference of the walls. The overall heat transfer coefficient and the surface area are assumed to be constant. The temperature difference over the walls however is not constant and is being measured. To calculate the total power leakage, the calibration curve in (8) is taken into account. The uncertainty is therefore not only depending on the error of the linear fit of the curve but also on the uncertainty of the temperature difference measurement. Hence, the relative fault on the power leakage is equal to (13)

$$
R F\left(P_{\text {walls }}\right)=\sqrt{R F\left(\text { Curve }_{\text {error }}\right)^{2}+R F\left(\Delta T_{\text {walls }}\right)^{2}}
$$

Hence, the uncertainty of the difference in power leakage through the walls of the main $\left(P_{\text {walls,main }}\right)$ and balance ( $\left.P_{\text {walls,bal }}\right)$ test is equal to (14).

$$
A F\left(P_{\text {diff }, \text { walls }}\right)=\sqrt{A F\left(P_{\text {walls,main }}\right)^{2}+A F\left(P_{\text {walls,bal }}\right)^{2}}
$$

If the thermal properties during the main and balance test are perfectly the same, the sum of the heater and the difference in leakage power through the walls is equal to the power loss of the DUT but this is never exactly the case [3]. The variation of humidity, pressure or temperature changes the specific heat capacity. As seen in (1), variations of the specific heat have an influence on the absorbed power. The percentage variation due to the temperature change is measured and therefore the variation on the power is calculated. This results in a compensation power ( $\left.P_{\text {comp }}\right)$ which is usually small. Hence, the uncertainty of $\mathrm{P}_{\text {comp }}$ is almost negligible.

Thus, the absolute fault on the power loss of the DUT can be calculated with (11). The uncertainty calculation is still not complete because the humidity and pressure of the inlet air are not measured but these would be very small and can therefore be neglected, especially when the standard uncertainty is multiplied with a coverage factor $(\mathrm{k})$ [8]. The expanded uncertainty when a normal distribution is applied with a coverage factor of two gives a $95 \%$ level of confidence that the error lies in that interval [10]. The uncertainty on the power loss would then be equal to (15)

$$
A F\left(P_{\text {loss }, \text { DUT }}\right)=k * \sqrt{A F\left(P_{\text {heater }, \text { bal }}\right)^{2}+A F\left(P_{\text {heater, main }}\right)^{2}+A F\left(P_{\text {diff }, \text { wall }}\right)^{2}+A F\left(P_{\text {comp }}\right)^{2}}
$$

with $\mathrm{k}$ the coverage factor. 


\section{Measurement results}

Two tests are executed and the results are processed. The first test is at the full load and speed and the second test at $100 \%$ load and $25 \%$ speed. The input-output and calorimetric measurements are performed simultaneously and compared. In figure 4, the temperatures, heater power, blower speed and power leakage through the walls of the test at nominal load and speed are shown. The progress of the measurement is clearly visible on these plots with at first the initialization (1), then the main test (2) and at last the balance test (3).

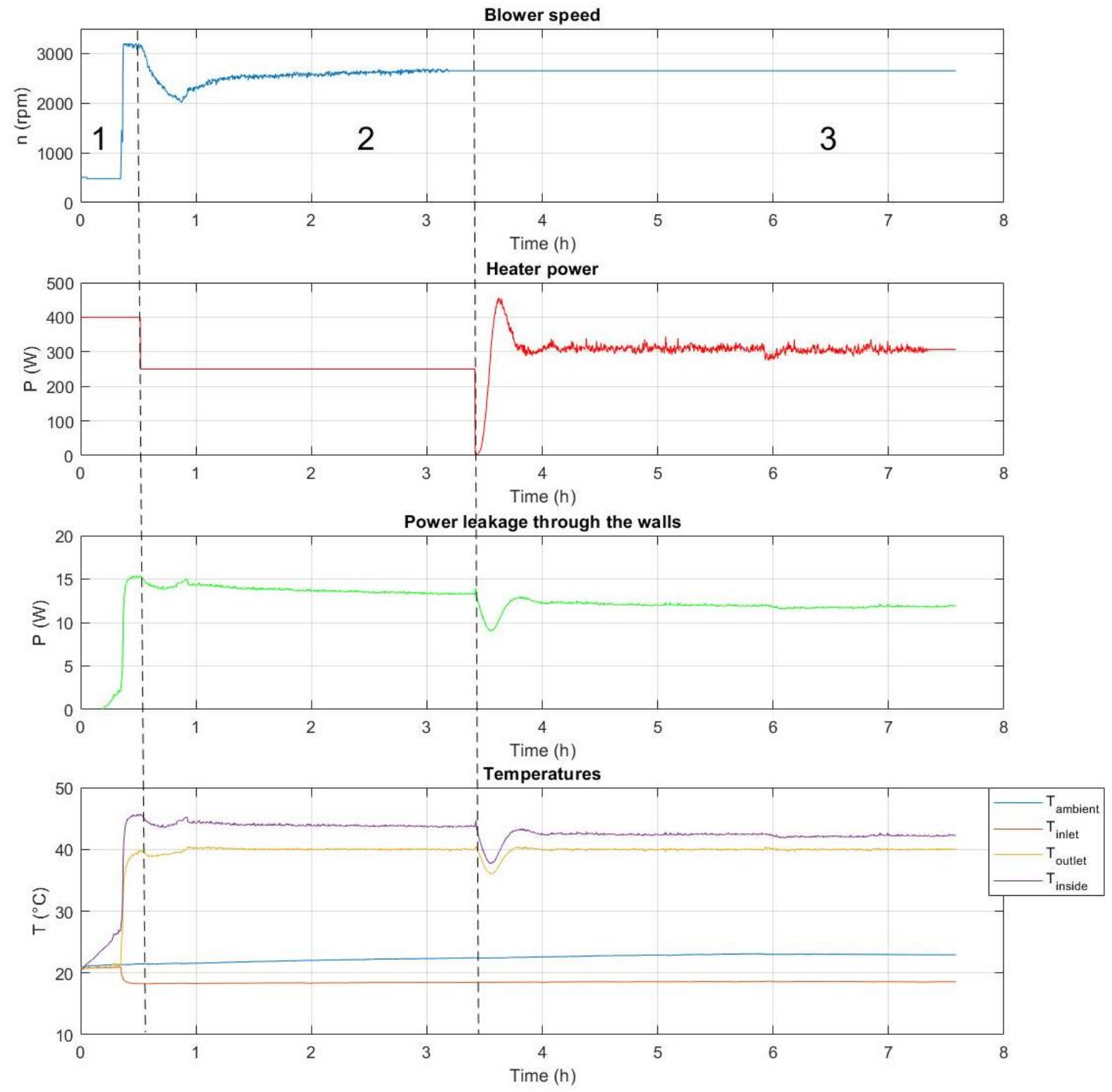

Figure 4: blower speed, heater power, leakage power and temperature plots of $100 \%$ load and $100 \%$ speed test. The initialization (1), the main test (2) and balance test (3) are indicated on the figure.

In table 2, the measurement results of the $100 \%$ load and speed test are shown. It is noticed that the temperature rise of the air during both tests is almost identical while the temperature difference over the walls changes. Therefore a difference in power leakage through the walls $1,44 \mathrm{~W}$ is determined. This difference is compensated when the results are processed in table 3 . It should also be noticed that the heater dissipates heat during the two measurement phases to decrease the test duration. An uncertainty due to the extra heater power in the main test is added to the total uncertainty. There are also variations in air temperature during the measurement. A compensation power of $1,27 \mathrm{~W}$ is added to the power loss. 
Table 2: measurement results of $100 \%$ load and $100 \%$ speed test

\begin{tabular}{|l|r|r|r|}
\cline { 2 - 4 } \multicolumn{1}{c|}{} & \multicolumn{1}{c|}{ Main test } & \multicolumn{1}{c|}{ Balance test } & \multicolumn{1}{c|}{ Difference } \\
\hline $\mathrm{T}_{\text {inlet }}\left({ }^{\circ} \mathrm{C}\right)$ & 18,45 & 18,56 & 0,11 \\
\hline $\mathrm{T}_{\text {outlet }}\left({ }^{\circ} \mathrm{C}\right)$ & 39,99 & 40,01 & 0,02 \\
\hline$\Delta \mathrm{T}_{\text {rise }}\left({ }^{\circ} \mathrm{C}\right)$ & 21,54 & 21,45 & 0,09 \\
\hline $\mathrm{T}_{\text {inside }}\left({ }^{\circ} \mathrm{C}\right)$ & 43,72 & 42,20 & 1,51 \\
\hline $\mathrm{T}_{\text {ambient }}\left({ }^{\circ} \mathrm{C}\right)$ & 22,40 & 22,93 & 0,53 \\
\hline$\Delta \mathrm{T}_{\text {walls }}\left({ }^{\circ} \mathrm{C}\right)$ & 21,31 & 19,27 & 2,04 \\
\hline $\mathrm{P}_{\text {heater }}(\mathrm{W})$ & 247,72 & 307,19 & 59,47 \\
\hline $\mathrm{P}_{\text {walls }}(\mathrm{W})$ & 13,30 & 11,86 & 1,44 \\
\hline $\mathrm{P}_{\text {comp }}(\mathrm{W})$ & & 1,27 & \\
\hline $\mathrm{P}_{\text {input }}(\mathrm{W})$ & 2277,26 & & \\
\hline $\mathrm{P}_{\text {output }}(\mathrm{W})$ & 2209,87 & & \\
\hline
\end{tabular}

In table 3, the measurement results of the two tests at $100 \%$ load and speed and at $100 \%$ load and $25 \%$ speed are shown. During the first test, the difference in power loss determined by both methods is $5,21 \mathrm{~W}$. The efficiency difference is much smaller due to the fact that the input power is taken into account when the efficiency is calculated. The difference in power loss of the second test is only $0,22 \mathrm{~W}$. The uncertainty of the measured power loss with the calorimeter is remarkably much lower than when the direct or input-output method is applied.

The uncertainty of the power loss determined with the direct method is $12,44 \mathrm{~W}$ for the first test and only $1,48 \mathrm{~W}$ when the calorimetric method is used. The uncertainty of the power loss with the direct method in the second test is $3,80 \mathrm{~W}$ and for the calorimetric result $1,42 \mathrm{~W}$. It should be noticed that the uncertainty on the power loss determined by the calorimeter does not change much when the DUT is more efficient. On the other hand, the input-output method is more accurate when the DUT is less efficient, as can be seen in the results in table 3 [1].

The difference in uncertainty on the efficiency between both methods is not that large because the input power is taken into account to calculate the efficiency value.

Table 3: measurement results of direct and calorimetric measurements

\begin{tabular}{|c|c|c|c|c|c|}
\hline & \multicolumn{2}{|c|}{$100 \%$ load, $100 \%$ speed } & \multicolumn{2}{|c|}{$25 \%$ load, $100 \%$ speed } \\
\hline & & Value & Uncertainty & Value & Uncertainty \\
\hline \multirow{5}{*}{$\begin{array}{l}\text { Input - output } \\
\text { measurement }\end{array}$} & $P_{\text {in }}$ & $2277,26 \mathrm{~W}$ & $\pm 8,01 \mathrm{~W}$ & $564,90 \mathrm{~W}$ & $\pm 3,07 \mathrm{~W}$ \\
\hline & Pout & $2209,87 \mathrm{~W}$ & $\pm 9,52 \mathrm{~W}$ & $501,88 \mathrm{~W}$ & $\pm 2,24 \mathrm{~W}$ \\
\hline & $P_{\text {out-in,DUT }}$ & $67,39 \mathrm{~W}$ & $\begin{array}{r} \pm 12,44 \mathrm{~W} \text { or } \\
\pm 18,46 \% \\
\end{array}$ & $63,01 \mathrm{~W}$ & $\begin{array}{r} \pm 3,80 \mathrm{~W} \text { or } \\
\pm 6,04 \% \\
\end{array}$ \\
\hline & $\eta_{\text {outin }}$ & $97,04 \%$ & $\pm 0,56 \%$ & $88,84 \%$ & $\pm 0,70 \%$ \\
\hline & $\begin{array}{l}\text { Measurement } \\
\text { duration }\end{array}$ & 30 minutes & & 30 minutes & \\
\hline \multirow{8}{*}{$\begin{array}{l}\text { Calorimetric } \\
\text { measurement }\end{array}$} & Pheater,main & $247,72 \mathrm{~W}$ & $\pm 0,66 \mathrm{~W}$ & $200,68 \mathrm{~W}$ & $\pm 0,58 \mathrm{~W}$ \\
\hline & $P_{\text {heater,bal }}$ & $307,19 \mathrm{~W}$ & $\pm 0,75 \mathrm{~W}$ & $258,81 \mathrm{~W}$ & $\pm 0,68 \mathrm{~W}$ \\
\hline & $P_{\text {heater }}$ & $59,47 \mathrm{~W}$ & $\pm 1,00 \mathrm{~W}$ & $58,14 \mathrm{~W}$ & $\pm 0,90 \mathrm{~W}$ \\
\hline & $P_{\text {diff,walls }}$ & $1,44 \mathrm{~W}$ & $\pm 1,12 \mathrm{~W}$ & $1,68 \mathrm{~W}$ & $\pm 1,10 \mathrm{~W}$ \\
\hline & $P_{\text {comp }}$ & $1,27 \mathrm{~W}$ & $\pm 0,02 \mathrm{~W}$ & $2,96 \mathrm{~W}$ & $\pm 0,05 \mathrm{~W}$ \\
\hline & Ploss,DUT & $62,18 \mathrm{~W}$ & $\begin{array}{r} \pm 1,48 \mathrm{~W} \text { or } \\
\pm 2,39 \%\end{array}$ & $62,79 \mathrm{~W}$ & $\begin{array}{r} \pm 1,42 \mathrm{~W} \text { or } \\
\pm 2,26 \%\end{array}$ \\
\hline & $\eta_{\text {calo }}$ & $97,27 \%$ & $\pm 0,51 \%$ & $88,89 \%$ & $\pm 0,87 \%$ \\
\hline & $\begin{array}{l}\text { Measurement } \\
\text { duration }\end{array}$ & 8 hours & & 4 hours & \\
\hline
\end{tabular}


It should be noticed that the measurement duration of the calorimetric tests is much longer than when the input-output method is performed.

\section{Conclusion}

In this paper a calorimeter test bench for the efficiency determination of power electronic variable speed drives is presented. This is an indirect balanced type with air as medium to test drives in a power range from $1 \mathrm{~kW}$ up to $7,5 \mathrm{~kW}$. First, a short introduction into the international standard IEC 61800-9-2 [1] is given. Secondly, the calorimeter concept is explained according to the balanced type. The test bench setup is also shown and discussed. Next, a flowchart with the measurement procedure is proposed to obtain correct results. Afterwards a measurement uncertainty calculation is shown and at last two tests are executed on the $2,2 \mathrm{~kW}$ drive and their results are presented.

The overall goal of this paper is to examine and optimize the calorimetric approach and to be able to obtain accurate results. The construction of a calorimeter is an intensive and difficult job. Compared to a power analyzer, it is cheaper in this power range but a lot of men hours are needed to finish such a construction.

The calorimetric approach is very time-consuming compared to the input-output measurements but this way of power loss determination is far more accurate when the power loss of a complete drive module is determined for IE classification compared to the direct approach. The calorimetric setup reaches a standard uncertainty of $2,39 \%$ or $1,48 \mathrm{~W}$ on the power loss while the direct method reaches $18,46 \%$ or $12,44 \mathrm{~W}$ during the same test on the same power loss. The accuracy of the calorimeter could even be increased when the heater would not be enabled during the main test.

There can be concluded that an uncertainty calculation for calorimetric measurements is not evident to execute because no standard method exists and comparing results with other publications is difficult. Therefore in this paper a thorough uncertainty calculation is presented.

A disadvantage of this setup is the variation of the ambient temperature. The power leakage through the walls varies due to this problem. The solution is to control the ambient air but this is not done yet. In general, the variation of the thermal conditions creates the largest uncertainty. This can be solved by measuring the air properties accurately and by controlling the inlet temperature of the air. 


\section{References}

[1] Adjustable speed electrical power drive systems - Part 9-2: Ecodesign for power drive systems, motor starters, power electronics \& their driven applications - Energy efficiency indicators for power drive systems and motor starters. Ed. 1. IEC 61800-2-9, March 2017.

[2] W. Cao, H. Zhang, G. M. Asher, X. Huang, I. French, J. Zhang and M. Short, "Calorimeters and Techniques Used for Power Loss Measurements in Electrical Machines," IEEE Instrumentation and Measurement Magazine, vol. 13, no. 6, pp. 26-33, 2010.

[3] A. Kosonen, L. Aarniovuori, J. Ahola, J. Backman, J. Pyrhönen and M. Niemelä, "Loss Definition of Electric Drives by a Calorimetric System With Data Processing," in IEEE Transactions on Industrial Electronics, vol. 61, no. 8, pp. 4432-4442, Aug. 2014

[4] H. Kärkkäinen, L. Aarniovuori, M. Niemelä and J. Pyrhönen, "Induction Motor Efficiency Verification Using a Balance-Type Calorimeter Equipped with a Mass Flow Meter," 20 $0^{\text {th }}$ European Conference on Power Electronics and Applications (EPE'18 ECCE Europe), at Riga, Latvia, Sept. 2018

[5] L. Aarniovuori, A. Kosonen, M. Niemelä and J. Pyrhönen, "Calorimetric measurement of variablespeed induction motor," 20th International conference on Electrical Machines (ICEM), Marseille, France, Sep. 2012, pp. 870-876

[6] D. Nair, S. Daryabin, S. Jannasch, A. Haavisto and A. Arkkio, "Design of water-cooled calorimeter for electric motor's power loss measurement," 2018 XIII International Conference on Electrical Machines (ICEM), at Greece, pp. 1142-1148, Sept. 2018

[7] L. Aarniovuori, H. Kärkkäinen, A. Kosonen, J. Pyrhönen, Z. Liu and W. Cao, "Overview of calorimetric systems used in loss determination of electric motors and drives," IECON 2017 $43^{\text {rd }}$ Annual Conference of the IEEE Industrial Electronics Society, Beijing, 2017, pp. 2110-2115

[8] Joint Committee for Guides in Metrology, "Evaluation of Measurement Data - Guide to the Expression of Uncertainty in Measurement (GUM)," 2008

[9] M. Kepsu, J. Pyrhönen, M. Niemelä and L. Aarniovuori, "Uncertainty of Efficiency Measurements in Electric Drives," 2015

[10] NIST, "Uncertainty of Measurement Results", Dec. 2017, [Online], Available: https://physics.nist.gov/cuu/Uncertainty/index.html, [Accessed 23 April 2018] 